\title{
Advances in Cell Transplantation Therapy for Diseased Myocardium
}

\author{
Outi M. Villet, ${ }^{1}$ Antti Siltanen, ${ }^{2}$ Tommi Pätilä, ${ }^{1}$ M. Ali A. Mahar, ${ }^{1,2}$ Antti Vento, ${ }^{1}$ \\ Esko Kankuri, ${ }^{2}$ and Ari Harjula ${ }^{1}$ \\ ${ }^{1}$ Department of Cardiothoracic Surgery, University of Helsinki Meilahti Hospital, P.O. Box 340, FIN-00029 HUS, Finland \\ ${ }^{2}$ Department of Pharmacology, Institute of Biomedicine, University of Helsinki, 00014 Helsinki, Finland
}

Correspondence should be addressed to Outi M. Villet, outivillet@gmail.com

Received 15 January 2011; Accepted 2 April 2011

Academic Editor: Wojciech Wojakowski

Copyright ( 2011 Outi M. Villet et al. This is an open access article distributed under the Creative Commons Attribution License, which permits unrestricted use, distribution, and reproduction in any medium, provided the original work is properly cited.

\begin{abstract}
The overall objective of cell transplantation is to repopulate postinfarction scar with contractile cells, thus improving systolic function, and to prevent or to regress the remodeling process. Direct implantation of isolated myoblasts, cardiomyocytes, and bone-marrow-derived cells has shown prospect for improved cardiac performance in several animal models and patients suffering from heart failure. However, direct implantation of cultured cells can lead to major cell loss by leakage and cell death, inappropriate integration and proliferation, and cardiac arrhythmia. To resolve these problems an approach using 3-dimensional tissue-engineered cell constructs has been investigated. Cell engineering technology has enabled scaffold-free sheet development including generation of communication between cell graft and host tissue, creation of organized microvascular network, and relatively long-term survival after in vivo transplantation.
\end{abstract}

\section{Introduction}

Cardiac repair by cell therapy offers hope to improve performance of diseased heart by reconstituting or maintaining cardiac specific tissue [1]. First studies were performed with cells such as myoblasts [2], but later the field expanded to several cell types including bone marrow cells [3], endothelial progenitors [4], mesenchymal stem cells (MSCs) [5], resident cardiac stem cells [6], and embryonic stem cells [7]. Numerous preclinical studies have shown improved cardiac function in animal models of heart failure, but the underlying mechanisms of this improvement have remained obscure.

Nevertheless, the hypothesis that cardiac function in heart failure can benefit from cell therapy has gained extensive attention and preliminary clinical trials have been launched [8-14]. Miyagawa et al., reported their first clinical trial with combined cell therapy instead of single cell therapy for a patient based on their finding that combined cell therapy (both myoblasts and bone marrow mononuclear cells) has a more synergistic effect on severely damaged myocardium [15]. In this case recovery of cardiac function and histological changes were observed. However, they could not establish if the dramatic functional improvement was attributable to decreased left ventricle (LV) distension by a left ventricular assist system (LVAS) or to the cell transplantation due to lack of an appropriate control. The brain natriuretic peptide (BNP) levels were significantly lower after cell transplantation than under LVAS before cell transplantation [15]. However, for those patients with ischemic cardiomyopathy, LVAS implantation alone does not achieve sufficient recovery of myocardial function. After LVAS implantation, decreased LV distension contributed to the reduced cell diameter and lower BNP [15]. They also detected other changes such as improved regional diastolic function and vascular density in the targeted region, in addition to the changes evoked by LVAS implantation. This indicates that cell transplantation had a positive effect on the distressed ischemic myocardium. Yet, the mixed results received from the clinical studies have regained the interests for laboratory work. 
TABLE 1: Cell transplantation by intramyocardial injection and vascular infusion in clinical studies.

\begin{tabular}{|c|c|c|c|c|}
\hline \multicolumn{5}{|c|}{ Cell injection to myocardium } \\
\hline Cell type & $\times 10^{6}$ cells & Function & Remarks & \\
\hline Myoblast & $\ldots$ & $\uparrow$ & Arrhythmogenic potential & {$[20]$} \\
\hline Myoblast & 206 & No effect & Arrhythmogenic potential & {$[21]$} \\
\hline Myoblast & $400-800$ & No effect & Arrhythmia & {$[14]$} \\
\hline Myoblast & 870 & $\ldots$ & Arrhythmogenic potential & {$[22]$} \\
\hline Myoblast, BMSC & 300,100 & $\uparrow$ & & {$[15]$} \\
\hline \multicolumn{5}{|c|}{ Vascular infusion } \\
\hline Cell type & $\times 10^{6}$ cells & Function & Remarks & \\
\hline BMSC & $\sim 1.5-9$ & $\ldots$ & Restoration of coronary flow reserve & {$[12]$} \\
\hline BMSC & 39 & $\uparrow$ & & {$[13]$} \\
\hline BMSC & 68 & No effect & & {$[11]$} \\
\hline BMSC & $\sim 100-300$ & $\uparrow$ & Lower mortality & {$[8]$} \\
\hline BMSC & $200-400$ & No effect & Infarct remodelling & {$[10]$} \\
\hline BMSC & $56-60000$ & $\uparrow$ & & [9] \\
\hline
\end{tabular}

BMSC: bone marrow stem cell.

\section{Cell Delivery by Injection}

One of the crucial issues in cell therapy for heart failure has been the cell delivery route. Injection of the cells has been the most typical method in clinical feasibility studies (Table 1). The cells have been injected directly into the myocardium or into the coronary vasculature. However, several underlying issues make this a challenging technique to use clinically. The injected cells can be washed out through channel leakage and the vascular system, creating a significant loss of grafted cells [16-18]. Additional loss of the grafted cells is generated by the disruption of the extracellular matrix and the subsequent loss of signals that modulate cell survival, differentiation, and patterning [19].

In addition, arrhythmogenicity of intramyocardial myoblast transplantation has aroused debate. Episodes of ventricular tachycardia and fibrillation have been noted after several feasibility studies. Due to small number of patients in nonrandomized series and the arrhythmogenic nature of the heart disease itself, direct causality is difficult to conclude. In an early study of Menasché et al., 4 out of 10 patients experienced sustained ventricular tachycardia [22], and in the study by Smits et al., 4 out of 15 patients experienced clinically significant arrhythmias in the early phase [20]. A four-year surveillance of the patients showed more intracardiac defibrillator (ICD) interventions when compared to a matched patient population [21]. According to the preliminary data, all patients in MAGIC trial received an ICD implant. At one year after the myoblast injections, no significant difference was found between the myoblasttreated group or the control group regarding arrhythmogenicity [14]. To overcome this evident problem, several strategies for preventing cell therapy-associated arrhythmias have been introduced. Genetic engineering by overexpressing connexin- 43 by the transplanted cells might improve the cell graft integration to the host [23]. Myocardial damage resulting from multiple needle injections is potentially a significant cause to ventricular arrhythmias. Avoiding the injections by using intracoronary delivery might decrease arrhythmia [24], although cell loss has been described [25]. Still, even more important aspect would be to improve the method of cell delivery. Various cell types and their delivery methods into damaged myocardium are compared in Table 2.

\section{Cell Delivery by Injection versus Cell Sheets}

Another approach for cell delivery as opposed to injection involves tissue-engineered constructs. The main advantage of this technology over standard cell implantation lies on the preservation of microcellular communication and matrix, which is lost upon trypsin treatment in the typical procedure of cell preparation. Epicardial deposition of cell sheets might be a solution to prevent significant cell loss and arrhythmia after cell transplantation [26]. Memon et al., reported that myoblast sheet implantation improved global cardiac function to a greater extent than the injection of cell suspension [27]. Similarly, in a recent study, myoblast cell sheets were compared to direct injections of myoblast cells in ischemic heart failure (Patila et al., submitted). Holter monitoring showed more ventricular premature contractions in the cell injection group. Furthermore, epicardial electropotential mapping showed areas of electrical reentry in the injection sites. RT-PCR showed more inflammatory markers and more inflammatory cells accumulated at the infarct border area in the injection group, when compared to the cell sheet-treated animals (Patila et al., submitted).

\section{Cell Sheets in Diseased Heart}

Current tissue engineering methods allow us to reconstruct myocardial tissue grafts for clinical applications, though human fetal and neonatal cardiomyocytes are difficult to 
TABLE 2: Cell types and delivery methods in cardiac functional outcome.

\begin{tabular}{|c|c|c|c|c|c|}
\hline \multicolumn{6}{|c|}{ Cell injection to myocardium } \\
\hline Model & Cell type & $\times 10^{6}$ cells & Function & Remarks & \\
\hline Mouse & BMSC & $0.0175-0.1$ & $\uparrow$ & Regeneration & [1] \\
\hline Rat & BMSC & 10 & $\uparrow$ & Arrhythmogenicity & [24] \\
\hline Rat & BMSC & 20 & $\uparrow$ & & [23] \\
\hline Rat & $\mathrm{CM}$ & 0.2 & $\uparrow$ & Regeneration & [6] \\
\hline Rat & $\mathrm{CM}$ & 5 & $\ldots$ & Cell washout & {$[16]$} \\
\hline Rat & Myoblast & 1 & $\uparrow$ & Improved exercise capacity & [28] \\
\hline Rat & Myoblast & 2.3 & $\uparrow$ & & [29] \\
\hline Rat & Myoblast & 10 & $\uparrow$ & Arrhythmogenicity & [23] \\
\hline Rabbit & FB & & & $\uparrow$ diastolic, $\downarrow$ systolic performance & [30] \\
\hline Rabbit & Myoblast & & $\uparrow$ & & [30] \\
\hline Sheep & Myoblast & $\ldots$ & $\uparrow$ & & [31] \\
\hline Swine & BMSC & 100 & $\ldots$ & Cell washout & [17] \\
\hline Swine & BMSC & 100 & $\ldots$ & High cell homing & [25] \\
\hline \multicolumn{6}{|c|}{ Vascular infusion } \\
\hline Model & Cell type & $\times 10^{6}$ cells & Function & Remarks & \\
\hline Mouse & BMSC & 20 & $\ldots$ & Regeneration & [3] \\
\hline Rat & BMSC & 10 & $\uparrow$ & & {$[24]$} \\
\hline Swine & BMSC & 100 & $\ldots$ & Cell washout & [25] \\
\hline \multicolumn{6}{|c|}{ Cell sheets } \\
\hline Model & Cell type & $\mathrm{Nr}$ of sheets & Function & Remarks & \\
\hline Hamster & Myoblast & 2 layers & $\uparrow$ & Higher life expectancy & [32] \\
\hline Rat & AdMSC & Monolayer & $\uparrow$ & $\begin{array}{l}\text { Paracrine } \\
\text { pathways_angiogenesis }\end{array}$ & {$[33]$} \\
\hline Rat & AdMSC & Monolayer & $\uparrow$ & & [34] \\
\hline Rat & $\mathrm{CM}, \mathrm{SC}$ & Monolayer & $\uparrow$ & $\begin{array}{l}\text { Cell survival, proliferation, } \\
\text { differentiation }\end{array}$ & {$[35]$} \\
\hline Rat & $\mathrm{CM}, \mathrm{EC}$ & "Monolayer" & $\uparrow$ & Higher vessel density & [36] \\
\hline Rat & $\mathrm{CM}$ & 2 monolayers & $\uparrow$ & $\begin{array}{l}\text { Integration of graft and } \\
\text { myocardium }\end{array}$ & {$[37]$} \\
\hline Rat & $\mathrm{CM}$ & Bilayer & & Functional integration & [26] \\
\hline Rat & $\mathrm{CM}$ & 3 monolayers & $\cdots$ & $\begin{array}{l}\text { Integration of graft and } \\
\text { myocardium }\end{array}$ & {$[38]$} \\
\hline Rat & $\mathrm{CM}$ & 3 monolayers & $\cdots$ & Thick grafts, multiple surgeries & [39] \\
\hline Rat & $\mathrm{FB}, \mathrm{EC}$ & 3 monolayers & $\uparrow$ & Less fibrosis & {$[40]$} \\
\hline Rat & Myoblast & 1-5 monolayers & $\uparrow$ & Dose-response & [41] \\
\hline Rat & Myoblast & 2 monolayers & $\uparrow$ & Less fibrosis, remodeling & [27] \\
\hline Rat & Myoblast & 2 layers & $\uparrow$ & $\begin{array}{l}\text { Less fibrosis, higher vessel } \\
\text { density }\end{array}$ & {$[42]$} \\
\hline Rat & Myoblast & $2 \times 5$ layers & $\uparrow$ & Higher vessel density & [43] \\
\hline Rat & Myoblast & $2 \times 5$ layers & $\uparrow$ & $\begin{array}{l}\text { Paracrine pathways- } \\
\text { angiogenesis }\end{array}$ & {$[44]$} \\
\hline Swine & Myoblast & 2-10 layers & $\uparrow$ & & [45] \\
\hline
\end{tabular}

AdMSC: adipose tissue-derived mesenchymal stem cell, BMSC: bone marrow stem cell, CM: cardiomyocyte, EC: endothelial cell, FB: fibroblast, SC: stromal cell.

obtain. Therefore, several classes of stem cells are being investigated as a potential cell source. Despite their attractive potential to differentiate into various cell types, several issues remain, including difficulties in obtaining and amplifying the cells and the lack of understanding of the mechanisms for differentiation and proliferation. Consequently, the clinical cell sheet transplantation has mainly focused on utilization of myoblasts.

Memon et al., [27] reported the use of skeletal myoblast sheets in a rat myocardial infarction model. Preclinical data 
have shown that autologous skeletal myoblasts are capable not only of fusion and differentiation into striated muscle cells within damaged myocardium [31] but also of augmenting systolic and diastolic performance in animal models of acute myocardial infarction and heart failure [28-30, 46]. Inhibition of apoptosis in myoblast sheets by expression of antiapoptotic $b c l 2$ was shown to enhance the efficacy of sheet transplantation therapy in acute myocardial infarction [43]. Moreover, Siltanen et al. demonstrated that prevention of graft apoptosis by $b c l 2$ improved myoblast sheet transplantation therapy also in chronic myocardial infarction model [44].

Dilated cardiomyopathy (DCM) is characterized by global myocardial remodeling, which mainly consists of myocardial fibrosis associated with changes in the cytoskeletal and sarcolemmal proteins in cardiomyocytes, leading to a reduction in the number and function of these cells [47]. Consequently, cardiac remodeling chronically progresses with ventricular dilation and thinning, leading to progressive congestive heart failure. Kondoh et al. used human hereditary DCM representative model of TO-2 hamster strain [32]. In this hamster strain, the number of cardiomyocytes decreases progressively because of apoptosis after birth, and cardiac remodeling, which mainly consists of myocardial fibrosis, occurs with ventricular dilation and thinning, leading to progressive congestive heart failure. Transplantation of myoblast sheet grafts showed reorganization of the cytoskeletal proteins, reduction of myocardial fibrosis, and prevention of dilation of the left ventricle, leading to prolonged life expectancy and a longer preservation of cardiac performance in the impaired heart.

Hoashi et al., [42] showed that myoblast sheet transplantation improved right ventricular diastolic dysfunction. Briefly, animals underwent pulmonary artery banding thus created chronic pressure overload resulting in right ventricular failure. Chronic pressure overload is one of the major risk factors of right ventricular dysfunction. In this situation the right ventricle is hypertrophied and systolic function is initially preserved, whereas diastolic function gradually deteriorates. Prolonged exposure to excessive pressure overload results in irreversible right ventricular failure. Thus they successfully demonstrated improvement in diastolic dysfunction and suppressed ventricular fibrosis with increased capillary density in a rat model of a pressure-overloaded right ventricle by implanting myoblast sheets.

Preclinical studies in impaired porcine heart using single monolayer skeletal muscle cell sheet demonstrated improved cardiac performance accompanied with increased myocardial perfusion and viable myocardial tissue [45].

Further, Miyahara et al., used mesenchymal stem cells (MSCs) derived from adipose tissue in a rat myocardial infarction model [33]. MSC sheets incorporated into the host myocardium and improved cardiac function and increased survival. Similarly, Okura et al., showed that transplanted sheets of adipose tissue-derived MSCs differentiated into cardiomyoblast-like cells and resulted in recovery of cardiac function and improved survival rate of rat with infarcted heart [34].

\section{Development of Complex Sheet Structures}

Difficulties still exist in the outcome of cell therapy, as it is challenging to control the cell growth and localization of the grafted cells and to deliver a cell sheet patch that significantly aids the function of the damaged myocardium. To overcome these problems research has begun on fabricating three-dimensional cardiac grafts composed of multilayered cell sheets. Several methods have been studied with reconstructed tissues based on biodegradable scaffolds, such as poly(lactic-co-glycolic acid) and gelatin or extracellular matrix components $[48,49]$.

5.1. Fabrication of Scaffold-Free Cell Sheets. In native cardiac tissue the cell density is considerably high, cells being tightly interconnected with gap junctions facilitating electrical communication. The use of scaffolds can lead to abnormal tissue development, electrical communication caused by insufficient cell-to-cell connections, inflammatory responses, and fibrous tissue formation. Alternatively, fabrication of scaffold-free cell sheets requires means of cell detachment from the culture surface that will preserve cell morphology, orientation within the scaffold, and adhesion to surrounding cells and the extracellular matrix. One way to achieve such detachment is to covalently employ a temperature-responsive polymer on cell culture surface. Poly(N-isopropylacrylamide) (PIPAAm) is a hydrophobic polymer at temperatures above $32^{\circ} \mathrm{C}$ which-after grafting to cell culture dishes - allows cell adhesion and proliferation [50]. At temperatures below $32^{\circ} \mathrm{C}$, PIPAAm grafted surfaces change their properties and become hydrophilic to allow cell detachment as intact sheets which harbor the ECM on the basal surface [51]. These sheets retain their cell-to-cell as well as cell-to-ECM adhesions [51], while cell viability is not compromised [50]. Further, PIPAAm-grafted surfaces can be used to engineer monolayer [52] as well as three-dimensional sheet structures comprised of several cell layers [53].

Stevens et al., and Itabashi et al., described other methods for creating scaffold-free sheets. Stevens et al., created embryonic stem cell-derived cardiomyocyte sheets utilizing Tefloncoated low-attachment tissue culture dishes combined with rotating orbital shaker [54]. The diameter of these sheets was dependent on cell number, and the thickness was approximately 300-600 $\mu \mathrm{m}$. These sheets, however, were subject to necrosis due to limited oxygen supply. The same method was then used to create prevascularized sheets composed of cardiomyocytes, endothelial cells, and fibroblasts. These sheets effectively integrated with the coronary circulation after implantation and evaded necrosis. Furthermore, Itabashi et al., fabricated cardiomyocyte sheets using polymerized fibrin-coated culture dishes [55]. This method is based on the proteolytic activity of the cardiomyocytes that degrades the underlying fibrin coating and allows harvesting of intact sheets mechanically using a cell scraper.

5.2. Cellular Communication in Cell Sheets. In addition to cell-to-cell communication, the layers need to establish a connection with each other and with the host tissue. Using 
a multielectrode extracellular recording system, Haraguchi et al., demonstrated that the electrical coupling between 2 sheets starts approximately 34 minutes after initial layering and is completed by about 46 minutes. They also showed small molecule exchange through gap junctions and presence of connexin-43 within 30 minutes of layering [56].

When Shimizu et al., implanted a 4-layered neonatal rat cardiomyocyte sheet into the subcutaneous space of nude rats, synchronous beating [57] and survival up to 1 year [58] were observed. The implanted graft showed characteristic structures of heart tissue, including elongated cardiomyocytes, well-differentiated sarcomeres, and gap junctions. Additionally, conduction velocity, contractile force, and size of implanted grafts increased in proportion to the host's growth [58]. Hata et al., further showed synchronous contraction with defined direction of neonatal rat cardiomyocyte sheets on decellularised porcine small-intestinal submucosa [59].

Miyagawa and colleagues showed that neonatal cardiomyocyte sheets fabricated on temperature-responsive culture dishes attached to the infarcted myocardium and led to an improvement in cardiac performance and improved vascular density [37]. The implanted sheets communicated with the host myocardium as indicated by the presence of connexin43 and changes in the QRS wave and action potential amplitude.

Another study demonstrated a similar electrical integration between a neonatal myocyte sheet and the host myocardium without serious arrhythmia [26]. Furthermore, histological analyses in infarcted rat hearts with a transplanted 3D tissue graft showed bridging of the cardiomyocytes with functional gap junctions and intercalated disks [38].

\subsection{Recreation of Microvessels and Cell Sheet Survival. Heart} is a metabolically active organ that requires virtually constant oxygen supply in order to function in a normal fashion. The major limitation of the multilayered cell grafts is insufficient circulation causing hypoxia, nutrient insufficiency, and accumulation of waste products. Cells in living tissues receive oxygen supply through a capillary network, whereas the cultured cell aggregates in vitro rely on diffusion. In order to reconstruct thicker and metabolically active tissue grafts sufficient blood supply network has to be created.

One strategy could be to generate capillary-like networks in vitro in tissue-engineered constructs before transplantation. Levenberg et al., demonstrated the induction of endothelial vessel networks in engineered skeletal muscle tissue constructs using a 3D culture system consisting of myoblasts, embryonic fibroblasts, and endothelial cells coseeded on porous, biodegradable polymer scaffolds [60]. Similar spontaneous $3 \mathrm{D}$ prevascular network formation has been shown also in in vitro bone coculture model with human MSCs, human umbilical vein endothelial cells (HUVECs) [61, 62], and in human endothelialized reconstructed skin (ERS), including keratinocytes, fibroblasts, and endothelial cells in a collagen sponge [63]. As the reconstructed skin was transplanted to a nude mouse, Tremblay et al., concluded that the early vascularization observed in the ERS was most likely the result of inosculation of the capillary-like structures with the host's capillaries, rather than neovascularisation, which is a slower process.

Sasagawa et al., developed a novel cell sheet stacking manipulation technique to create multilayered cell sheets from human skeletal muscle myoblasts [64]. They placed a hydrogel-coated plunger onto a confluently cultured cell layer in a temperature-responsive culture dish. To harvest the cell layer the temperature was decreased to $20^{\circ} \mathrm{C}$ after which the plunger with the cell layer was transferred onto another confluent myoblast monolayer in another dish and incubated at $37^{\circ} \mathrm{C}$ to promote the cell layer adhesion. After $30-50$ minutes in $20^{\circ} \mathrm{C}$ the plunger was lifted up with a double-layer myoblast sheet. They were able to reach a 5layered construct with this procedure, which did no harm to the cells confirmed by cell viability assay. To further develop a viable cell dense tissue construct Sasagawa et al., sandwiched HUVECs into the 5-layer myoblast sheet construct. Four days after culture, the HUVECs had started to develop into capillary-like structures. One week after the constructs were engrafted on the dorsal subcutaneous tissue of nude rat, newly formed microvessels connected to the host vessels were found.

A single myoblast layer is about $45 \mu \mathrm{m}$ thick [57]. Accordingly, most previous studies used multilayer constructs up to about $250 \mu \mathrm{m}$ thick. In order to progress the human cell sheet applications the greater thickness of the construct would be of great advantage. Sekiya et al., investigated the relationship between the number of transplanted cell layers and cardiac function. They found a significant improvement of cardiac function, induction of angiogenesis, more elastic fibers, and less fibrosis with implantation of 3- and 5- layered myoblast sheets compared to single layer [41].

Shimizu et al., showed that the 1-, 2-, and 3-layer constructs transplanted into the dorsal subcutaneous tissue of nude rats thoroughly survived without necrosis [39]. However, parts of the 4- and 5-layer constructs showed disordered vasculature and connective tissue, indicative of necrosis. Subsequently, transplantation of two triple-layer grafts at 1-day intervals permitted whole tissue survival with a well-organized microvascular network, whereas 2and 3-day transplantation intervals had poor outcome. Shimizu et al., further developed the polysurgical method by transplanting up to 10 triple-layer cell sheet grafts at 1or 2-day intervals. Interestingly, at one week after the final transplantation about $0.9 \mathrm{~mm}$ thick cell-dense myocardium graft revealed vigorous myocardium-like pulsation with wellorganized microvessels throughout the graft. This polysurgical method would encounter difficulties in clinical replacement therapy as each procedure has a relatively high risk of complications. To overcome this obstacle, Shimizu et al., developed an ectopic construct repeatedly transplanting the layered cell sheets over an exposed superficial caudal epigastric, and femoral artery and vein of a nude rat. After 2 weeks the pulsating graft was resected together with the femoral artery and vein and further connected to carotid artery and the jugular vein in a new host. The grafts survived and maintained their characteristic beating 2 weeks after the procedure. 
5.4. Angiogenesis in Cell Sheets. One way to enhance the cell sheet graft survival is to promote angiogenesis. Enhanced angiogenesis and functional improvement were achieved by using cocultured cell sheets with fibroblasts and endothelial progenitor cells [40]. Another study showed an accelerated secretion of angiogenic factors in vitro and increased blood perfusion in vivo by using a coculture of fibroblasts and human smooth muscle cells [65]. In addition, Sekine et al., showed that a coculture of cardiomyocytes and endothelial cells in a cell sheet enhanced vascularization and that the implanted sheet improved cardiac performance compared with a cardiomyocyte-only sheet [36].

Stimulation of angiogenesis has also been shown in single cell-type cell sheets. Miyagawa et al., demonstrated that human HGF gene transfection enhanced the cellular cardiomyoplasty likely by stimulating angiogenesis, restoring the impaired extracellular matrix, and promoting the integration of the dissociated grafted myocytes [66]. Zakharova et al., fabricated sheets from cardiac progenitor cells and showed that these sheets improved cardiac function, suppressed wall thinning, and increased vascular density [35].

To understand the molecular mechanisms of cell sheet angiogenesis Sekiya et al., studied both in vitro and in vivo models and demonstrated that cardiac cell sheets express VEGF, Cox-2, and Tie-2 and exhibit endothelial cell organisation and microvessel formation [67]. Kitabayashi et al., showed that myoblast sheets express proangiogenic VEGF and placental growth factor and that implantation of these sheets induces angiogenesis in vivo. Expression of these proangiogenic genes was further induced by preventing graft apoptosis with antiapoptotic gene therapy [43]. Moreover, Siltanen et al., showed that the proangiogenic effect of myoblast sheets is mediated via the Flt1/Flk-1 pathway [44]. Memon et al., reported expression of SDF-1, HGF, and VEGF in the myocardium after myoblast sheet transplantation [27]. Finally, expression of human HGF in myoblast sheets further enhanced the proangiogenic potential of myoblast sheet therapy [68]. In this study, HGF-expressing sheet therapy increased vascular density in the infarct and border area, as well as in the noninfarcted myocardium.

\section{Conclusion}

Difficulties in reproducibility in cell injection therapy, including low survival and function of the cells, have led to search for more robust methods. Engineering of $3 \mathrm{D}$ cell constructs has currently been under extensive investigation. Preassembled cell constructs might provide effective tools for the future cell therapy research. Establishment of programmable materials used in the cell engineering technology has enabled the creation of scaffold-free cell sheets in a rather simple and inexpensive method. The main aspects of cell sheet construction that must be met for successful regenerative therapy are dynamic, electrical, and histological integration. Increased cell-to-cell communication and survival in cell sheets warrant further attention. The reviewed studies demonstrate the existing potential to produce viable, functional myocardial tissue implantable constructs well beyond the current diffusion-limited thickness regime.

\section{References}

[1] D. Orlic, J. Kajstura, S. Chimenti et al., "Bone marrow cells regenerate infarcted myocardium," Nature, vol. 410, no. 6829, pp. 701-705, 2001.

[2] R. C. J. Chiu, A. Zibaitis, and R. L. Kao, "Cellular cardiomyoplasty: myocardial regeneration with satellite cell implantation," Annals of Thoracic Surgery, vol. 60, no. 1, pp. 12-18, 1995.

[3] R. E. Bittner, C. Schöfer, K. Weipoltshammer et al., "Recruitment of bone-marrow-derived cells by skeletal and cardiac muscle in adult dystrophic mdx mice," Anatomy and Embryology, vol. 199, no. 5, pp. 391-396, 1999.

[4] T. Asahara, T. Murohara, A. Sullivan et al., "Isolation of putative progenitor endothelial cells for angiogenesis," Science, vol. 275, no. 5302, pp. 964-967, 1997.

[5] M. F. Pittenger, A. M. Mackay, S. C. Beck et al., "Multilineage potential of adult human mesenchymal stem cells," Science, vol. 284, no. 5411, pp. 143-147, 1999.

[6] A. P. Beltrami, L. Barlucchi, D. Torella et al., "Adult cardiac stem cells are multipotent and support myocardial regeneration," Cell, vol. 114, no. 6, pp. 763-776, 2003.

[7] M. V. Westfall, K. A. Pasyk, D. I. Yule, L. C. Samuelson, and J. M. Metzger, "Ultrastructure and cell-cell coupling of cardiac myocytes differentiating in embryonic stem cell cultures," Cell Motility and the Cytoskeleton, vol. 36, no. 1, pp. 43-54, 1997.

[8] B. Assmus, U. Fischer-Rasokat, J. Honold et al., "Transcoronary transplantation of functionally competent BMCs is associated with a decrease in natriuretic peptide serum levels and improved survival of patients with chronic postinfarction heart failure: results of the TOPCARE-CHD registry," Circulation Research, vol. 100, no. 8, pp. 1234-1241, 2007.

[9] S. L. Chen, WU. W. Fang, F. Ye et al., "Effect on left ventricular function of intracoronary transplantation of autologous bone marrow mesenchymal stem cell in patients with acute myocardial infarction," American Journal of Cardiology, vol. 94, no. 1, pp. 92-95, 2004.

[10] S. Janssens, C. Dubois, J. Bogaert et al., "Autologous bone marrow-derived stem-cell transfer in patients with STsegment elevation myocardial infarction: double-blind, randomised controlled trial," The Lancet, vol. 367, no. 9505, pp. 113-121, 2006.

[11] K. Lunde, S. Solheim, S. Aakhus et al., "Intracoronary injection of mononuclear bone marrow cells in acute myocardial infarction," The New England Journal of Medicine, vol. 355, no. 12 , pp. 1199-1209, 2006.

[12] V. Schächinger, B. Assmus, J. Honold et al., "Normalization of coronary blood flow in the infarct-related artery after intracoronary progenitor cell therapy: intracoronary Doppler substudy of the TOPCARE-AMI trial," Clinical Research in Cardiology, vol. 95, no. 1, pp. 13-22, 2006.

[13] K. C. Wollert, G. P. Meyer, J. Lotz et al., "Intracoronary autologous bone-marrow cell transfer after myocardial infarction: the BOOST randomised controlled clinical trial," The Lancet, vol. 364, no. 9429, pp. 141-148, 2004.

[14] P. Menasché, O. Alfieri, S. Janssens et al., "The myoblast autologous grafting in ischemic cardiomyopathy (MAGIC) trial: first randomized placebo-controlled study of myoblast transplantation," Circulation, vol. 117, no. 9, pp. 1189-1200, 2008. 
[15] S. Miyagawa, G. Matsumiya, T. Funatsu et al., "Combined autologous cellular cardiomyoplasty using skeletal myoblasts and bone marrow cells for human ischemic cardiomyopathy with left ventricular assist system implantation: report of a case," Surgery Today, vol. 39, no. 2, pp. 133-136, 2009.

[16] J. Dow, B. Z. Simkhovich, L. Kedes, and R. A. Kloner, "Washout of transplanted cells from the heart: a potential new hurdle for cell transplantation therapy," Cardiovascular Research, vol. 67, no. 2, pp. 301-307, 2005.

[17] H. Zhang, P. Song, Y. Tang et al., "Injection of bone marrow mesenchymal stem cells in the borderline area of infarcted myocardium: heart status and cell distribution," Journal of Thoracic and Cardiovascular Surgery, vol. 134, no. 5, pp. 12341240, 2007.

[18] W. Hudson, M. C. Collins, D. deFreitas, Y. S. Sun, B. MullerBorer, and A. P. Kypson, "Beating and arrested intramyocardial injections are associated with significant mechanical loss: implications for cardiac cell transplantation," Journal of Surgical Research, vol. 142, no. 2, pp. 263-267, 2007.

[19] F. N. Smets, Y. Chen, L. J. Wang, and H. E. Soriano, "Loss of cell anchorage triggers apoptosis (anoikis) in primary mouse hepatocytes," Molecular Genetics and Metabolism, vol. 75, no. 4, pp. 344-352, 2002.

[20] P. C. Smits, C. Nienaber, A. Colombo et al., "Myocardial repair by percutaneous cell transplantation of autologous skeletal myoblast as a stand alone procedure in post myocardial infarction chronic heart failure patients," EuroIntervention, vol. 1, no. 4, pp. 417-424, 2006.

[21] C. E. Veltman, O. I. I. Soliman, M. L. Geleijnse et al., "Fouryear follow-up of treatment with intramyocardial skeletal myoblasts injection in patients with ischaemic cardiomyopathy," European Heart Journal, vol. 29, no. 11, pp. 1386-1396, 2008.

[22] P. Menasché, A. A. Hagège, J. T. Vilquin et al., "Autologous skeletal myoblast transplantation for severe postinfarction left ventricular dysfunction," Journal of the American College of Cardiology, vol. 41, no. 7, pp. 1078-1083, 2003.

[23] S. R. Coppen, S. Fukushima, Y. Shintani et al., "A factor underlying late-phase arrhythmogenicity after cell therapy to the heart: global downregulation of connexin 43 in the host myocardium after skeletal myoblast transplantation," Circulation, vol. 118, no. 14, pp. S138-S144, 2008.

[24] S. Fukushima, A. Varela-Carver, S. R. Coppen et al., "Direct intramyocardial but not intracoronary injection of bone marrow cells induces ventricular arrhythmias in a rat chronic ischemic heart failure model," Circulation, vol. 115, no. 17, pp. 2254-2261, 2007.

[25] J. Mäkelä, V. Anttila, K. Ylitalo et al., "Acute homing of bone marrow-derived mononuclear cells in intramyocardial vs. intracoronary transplantation," Scandinavian Cardiovascular Journal, vol. 43, no. 6, pp. 366-373, 2009.

[26] A. Furuta, S. Miyoshi, Y. Itabashi et al., "Pulsatile cardiac tissue grafts using a novel three-dimensional cell sheet manipulation technique functionally integrates with the host heart, in vivo," Circulation Research, vol. 98, no. 5, pp. 705-712, 2006.

[27] I. A. Memon, Y. Sawa, N. Fukushima et al., "Repair of impaired myocardium by means of implantation of engineered autologous myoblast sheets," Journal of Thoracic and Cardiovascular Surgery, vol. 130, no. 5, pp. 1333-1341, 2005.

[28] M. Jain, H. DerSimonian, D. A. Brenner et al., "Cell therapy attenuates deleterious ventricular remodeling and improves cardiac performance after myocardial infarction," Circulation, vol. 103, no. 14, pp. 1920-1927, 2001.
[29] B. Pouzet, S. Ghostine, J.-T. Vilquin et al., "Is skeletal myoblast transplantation clinically relevant in the era of angiotensinconverting enzyme inhibitors?" Circulation, vol. 104, supplement 1, pp. i223-i228, 2001.

[30] K. A. Hutcheson, B. Z. Atkins, M. T. Hueman, M. B. Hopkins, D. D. Glower, and D. A. Taylor, "Comparison of benefits on myocardial performance of cellular cardiomyoplasty with skeletal myoblasts and fibroblasts," Cell Transplantation, vol. 9, no. 3, pp. 359-368, 2000.

[31] S. Ghostine, C. Carrion, L. C.G. Souza et al., "Long-term efficacy of myoblast transplantation on regional structure and function after myocardial infarction," Circulation, vol. 106, no. 12, supplement 1, pp. I131-I136, 2002.

[32] H. Kondoh, Y. Sawa, S. Miyagawa et al., "Longer preservation of cardiac performance by sheet-shaped myoblast implantation in dilated cardiomyopathic hamsters," Cardiovascular Research, vol. 69, no. 2, pp. 466-475, 2006.

[33] Y. Miyahara, N. Nagaya, M. Kataoka et al., "Monolayered mesenchymal stem cells repair scarred myocardium after myocardial infarction," Nature Medicine, vol. 12, no. 4, pp. 459-465, 2006.

[34] H. Okura, A. Matsuyama, C. M. Lee et al., "Cardiomyoblastlike cells differentiated from human adipose tissue-derived mesenchymal stem cells improve left ventricular dysfunction and survival in a rat myocardial infarction model," Tissue Engineering Part C, vol. 16, no. 3, pp. 417-425, 2010.

[35] L. Zakharova, D. Mastroeni, N. Mutlu et al., "Transplantation of cardiac progenitor cell sheet onto infarcted heart promotes cardiogenesis and improves function," Cardiovascular Research, vol. 87, no. 1, pp. 40-49, 2010.

[36] H. Sekine, T. Shimizu, K. Hobo et al., "Endothelial cell coculture within tissue-engineered cardiomyocyte sheets enhances neovascularization and improves cardiac function of ischemic hearts," Circulation, vol. 118, no. 14, pp. S145-S152, 2008.

[37] S. Miyagawa, Y. Sawa, S. Sakakida et al., "Tissue cardiomyoplasty using bioengineered contractile cardiomyocyte sheets to repair damaged myocardium: their integration with recipient myocardium," Transplantation, vol. 80, no. 11, pp. 15861595, 2005.

[38] H. Sekine, T. Shimizu, S. Kosaka, E. Kobayashi, and T. Okano, "Cardiomyocyte bridging between hearts and bioengineered myocardial tissues with mesenchymal transition of mesothelial cells," Journal of Heart and Lung Transplantation, vol. 25, no. 3, pp. 324-332, 2006.

[39] T. Shimizu, H. Sekine, J. Yang et al., "Polysurgery of cell sheet grafts overcomes diffusion limits to produce thick, vascularized myocardial tissues," FASEB Journal, vol. 20, no. 6, pp. 708-710, 2006.

[40] H. Kobayashi, T. Shimizu, M. Yamato et al., "Fibroblast sheets co-cultured with endothelial progenitor cells improve cardiac function of infarcted hearts," Journal of Artificial Organs, vol. 11, no. 3, pp. 141-147, 2008.

[41] N. Sekiya, G. Matsumiya, S. Miyagawa et al., "Layered implantation of myoblast sheets attenuates adverse cardiac remodeling of the infarcted heart," Journal of Thoracic and Cardiovascular Surgery, vol. 138, no. 4, pp. 985-993, 2009.

[42] T. Hoashi, G. Matsumiya, S. Miyagawa et al., "Skeletal myoblast sheet transplantation improves the diastolic function of a pressure-overloaded right heart," Journal of Thoracic and Cardiovascular Surgery, vol. 138, no. 2, pp. 460-467, 2009.

[43] K. Kitabayashi, A. Siltanen, T. Pätilä et al., "Bcl-2 expression enhances myoblast sheet transplantation therapy for acute myocardial infarction," Cell Transplantation, vol. 19, no. 5, pp. 573-588, 2010. 
[44] A. Siltanen, K. Kitabayashi, T. Pätilä et al., "Bcl-2 improves myoblast sheet therapy in rat chronic heart failure," Tissue Engineering Part A, vol. 17, no. 1-2, pp. 115-125, 2011.

[45] S. Miyagawa, A. Saito, T. Sakaguchi et al., "Impaired myocardium regeneration with skeletal cell sheets-a preclinical trial for tissue-engineered regeneration therapy," Transplantation, vol. 90, no. 4, pp. 364-372, 2010.

[46] D. A. Taylor, "Cell-based myocardial repair: how should we proceed?" International Journal of Cardiology, vol. 95, supplement 1, pp. S8-S12, 2004.

[47] N. E. Bowles, K. R. Bowles, and J. A. Towbin, "The 'final common pathway' hypothesis and inherited cardiovascular disease: the role of cytoskeletal proteins in dilated cardiomyopathy," Herz, vol. 25, no. 3, pp. 168-175, 2000.

[48] R. Langer and J. P. Vacanti, “Tissue engineering," Science, vol. 260, no. 5110, pp. 920-926, 1993.

[49] R. K. Li, Z. Q. Jia, R. D. Weisel, D. A. G. Mickle, A. Choi, and T. M. Yau, "Survival and function of bioengineered cardiac grafts," Circulation, vol. 100, no. 19, pp. II63-II69, 1999.

[50] T. Okano, N. Yamada, H. Sakai, and Y. Sakurai, "A novel recovery system for cultured cells using plasma-treated polystyrene dishes grafted with poly(N-isopropylacrylamide)," Journal of Biomedical Materials Research, vol. 27, no. 10, pp. 1243-1251, 1993.

[51] AI. Kushida, M. Yamato, C. Konno, A. Kikuchi, Y. Sakurai, and T. Okano, "Decrease in culture temperature releases monolayer endothelial cell sheets together with deposited fibronectin matrix from temperature-responsive culture surfaces," Journal of Biomedical Materials Research, vol. 45, no. 4, pp. 355-362, 1999.

[52] T. Shimizu, M. Yamato, A. Kikuchi, and T. Okano, "Twodimensional manipulation of cardiac myocyte sheets utilizing temperature-responsive culture dishes augments the pulsatile amplitude," Tissue Engineering, vol. 7, no. 2, pp. 141-151, 2001.

[53] T. Shimizu, M. Yamato, T. Akutsu et al., "Electrically communicating three-dimensional cardiac tissue mimic fabricated by layered cultured cardiomyocyte sheets," Journal of Biomedical Materials Research, vol. 60, no. 1, pp. 110-117, 2002.

[54] K. R. Stevens, K. L. Kreutziger, S. K. Dupras et al., "Physiological function and transplantation of scaffold-free and vascularized human cardiac muscle tissue," Proceedings of the National Academy of Sciences of the United States of America, vol. 106, no. 39, pp. 16568-16573, 2009.

[55] Y. Itabashi, S. Miyoshi, H. Kawaguchi et al., "A new method for manufacturing cardiac cell sheets using fibrin-coated dishes and its electrophysiological studies by optical mapping," Artificial Organs, vol. 29, no. 2, pp. 95-103, 2005.

[56] Y. Haraguchi, T. Shimizu, M. Yamato, A. Kikuchi, and T. Okano, "Electrical coupling of cardiomyocyte sheets occurs rapidly via functional gap junction formation," Biomaterials, vol. 27, no. 27, pp. 4765-4774, 2006.

[57] T. Shimizu, M. Yamato, Y. Isoi et al., "Fabrication of pulsatile cardiac tissue grafts using a novel 3-dimensional cell sheet manipulation technique and temperature-responsive cell culture surfaces," Circulation Research, vol. 90, no. 3, p. e40, 2002.

[58] T. Shimizu, H. Sekine, Y. Isoi, M. Yamato, A. Kikuchi, and T. Okano, "Long-term survival and growth of pulsatile myocardial tissue grafts engineered by the layering of cardiomyocyte sheets," Tissue Engineering, vol. 12, no. 3, pp. 499-507, 2006.

[59] H. Hata, A. Bär, S. Dorfman et al., "Engineering a novel threedimensional contractile myocardial patch with cell sheets and decellularised matrix," European Journal of Cardio-thoracic Surgery, 2010.
[60] S. Levenberg, J. Rouwkema, M. Macdonald et al., "Engineering vascularized skeletal muscle tissue," Nature Biotechnology, vol. 23, no. 7, pp. 879-884, 2005.

[61] J. Rouwkema, J. de Boer, and C. A. van Blitterswijk, "Endothelial cells assemble into a 3-dimensional prevascular network in a bone tissue engineering construct," Tissue Engineering, vol. 12, no. 9, pp. 2685-2693, 2006.

[62] N. Asakawa, T. Shimizu, Y. Tsuda et al., "Pre-vascularization of in vitro three-dimensional tissues created by cell sheet engineering," Biomaterials, vol. 31, no. 14, pp. 3903-3909, 2010.

[63] P. L. Tremblay, V. Hudon, F. Berthod, L. Germain, and F. A. Auger, "Inosculation of tissue-engineered capillaries with the host's vasculature in a reconstructed skin transplanted on mice," American Journal of Transplantation, vol. 5, no. 5, pp. 1002-1010, 2005.

[64] T. Sasagawa, T. Shimizu, S. Sekiya et al., "Design of prevascularized three-dimensional cell-dense tissues using a cell sheet stacking manipulation technology," Biomaterials, vol. 31, no. 7, pp. 1646-1654, 2010.

[65] K. Hobo, T. Shimizu, H. Sekine, T. Shin'oka, T. Okano, and H. Kurosawa, "Therapeutic angiogenesis using tissue engineered human smooth muscle cell sheets," Arteriosclerosis, Thrombosis, and Vascular Biology, vol. 28, no. 4, pp. 637-643, 2008.

[66] S. Miyagawa, Y. Sawa, S. Taketani et al., "Myocardial regeneration therapy for heart failure: hepatocyte growth factor enhances the effect of cellular cardiomyoplasty," Circulation, vol. 105, no. 21, pp. 2556-2561, 2002.

[67] S. Sekiya, T. Shimizu, M. Yamato, A. Kikuchi, and T. Okano, "Bioengineered cardiac cell sheet grafts have intrinsic angiogenic potential," Biochemical and Biophysical Research Communications, vol. 341, no. 2, pp. 573-582, 2006.

[68] A. Siltanen, K. Kitabayashi, P. Lakkisto et al., "hHGF overexpression in myoblast sheets enhances their angiogenic potential in rat chronic heart failure," PLoS One, vol. 6, no. 4, Article ID e19161, 2011. 

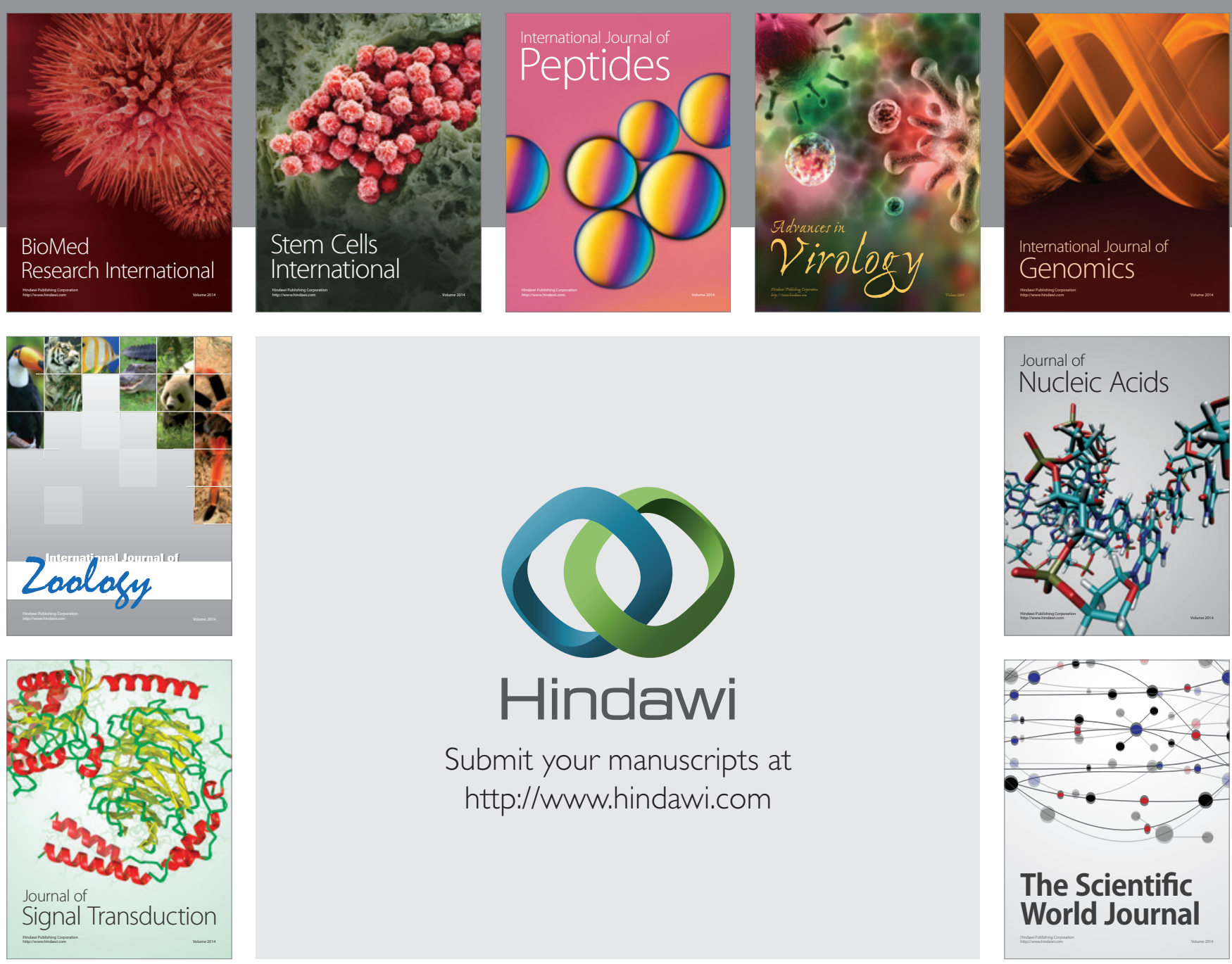

Submit your manuscripts at

http://www.hindawi.com
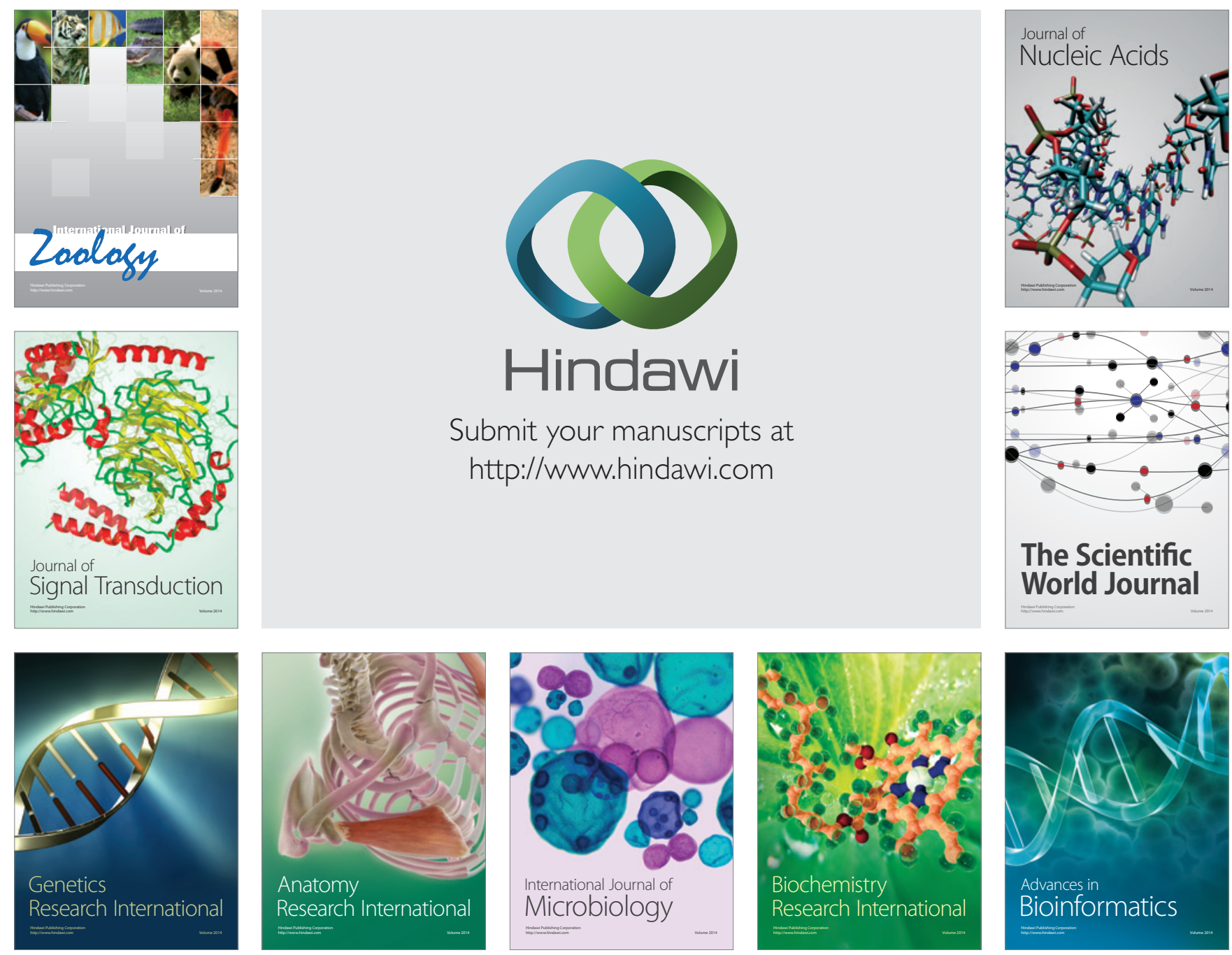

The Scientific World Journal
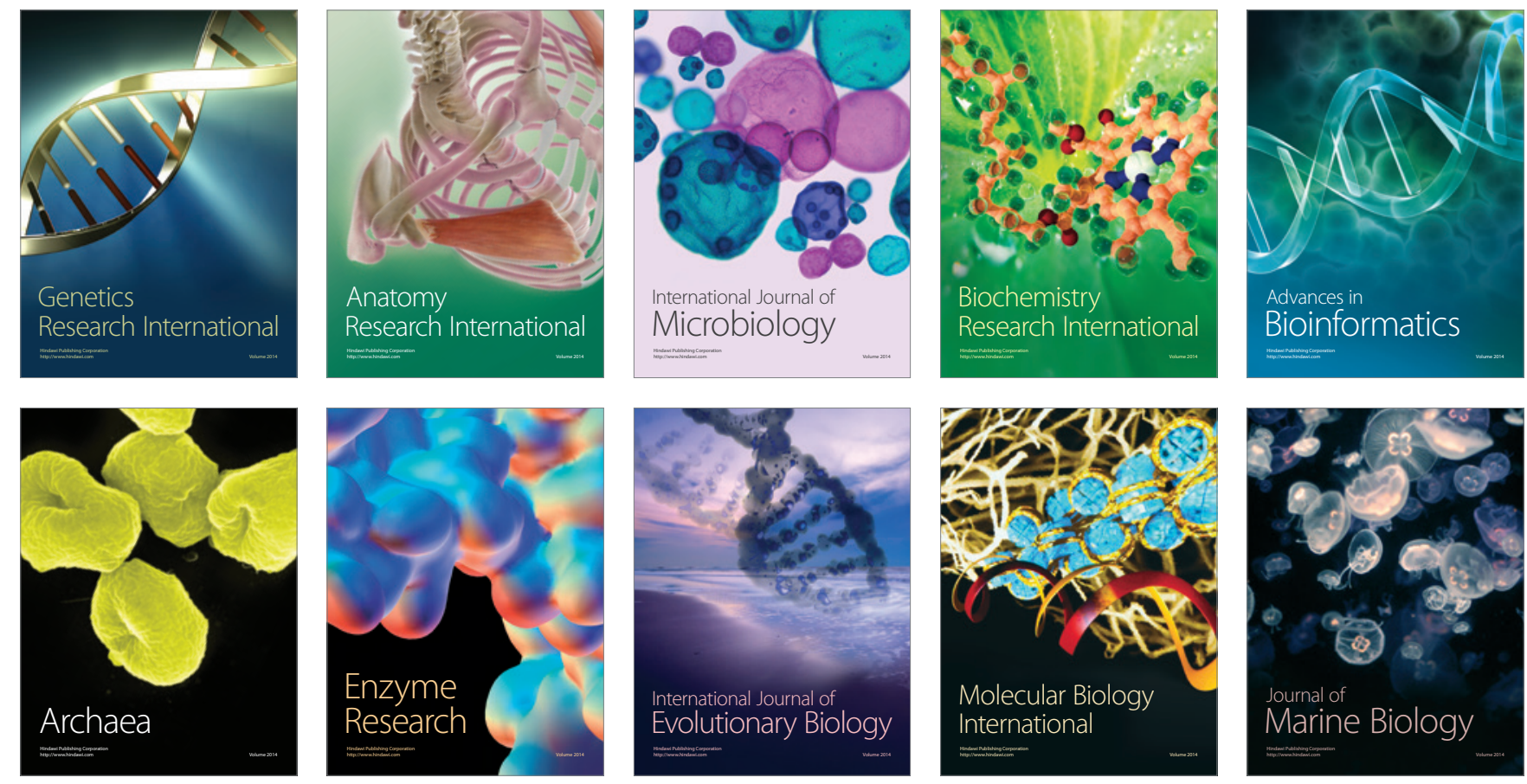